\title{
Laparoscopy-assisted Distal Gastrectomy with Systemic D2 Lymphadenectomy for Gastric Cancer: Usefulness of Noncompliance Rate to Validate the Completion of D2
}

\author{
Kyung Won Seo ${ }^{1}$, Kae Won Park ${ }^{2}$, Ki Young Yoon ${ }^{1}$ \\ ${ }^{I}$ Department of Surgery, College of Medicine, Kosin University, Busan, Korea \\ ${ }^{2}$ Postgraduate school, College of Medicine, Kosin University, Busan, Korea
}

\section{위암환자의 복강경보조하 위부분절제술에서 D2 림프절 절제술의 검증을 위한 비순응률의 유용성}

서경원 ${ }^{1} \cdot$ 박개원 $^{2} \cdot$ 윤기영 $^{1}$

${ }^{1}$ 고신대학교 의과대학 외과학교실, ${ }^{2}$ 고신대학교 대학원 의학과

Objectives: Laparoscopy-assisted distal gastrectomy (LADG) is a common surgical procedure that has recently been accepted as safe and feasible for the treatment of early gastric cancer. There have been many efforts to expand the indications of LADG to include the treatment of advanced gastric cancer. The aim of this study was to determine the usefulness of noncompliance rate as an indicator for D2 lymph node dissection (LND) validation in LADG.

Methods: The subjects were 48 patients who underwent distal gastrectomy with D2 LND at Kosin University Gospel Hospital from October to December 2010. Of them, 28 underwent LADG and 20 underwent open distal gastrectomy (ODG). We compared several factors including noncompliance rate to validate D2 LND.

Results: There were no significant differences in clinicopathologic factors except for BMI and tumor depth between the two groups. The average number of retrieved lymph nodes was significantly greater in the ODG group $(45.9 \pm 2.9)$ than in the LADG group $(35.5 \pm 2.0)$. The noncompliance rate was $43 \%$ in the LADG group and $40 \%$ in the ODG group with no significant difference.

Conclusions: In terms of no difference of noncompliance rate, LADG with D2 lymph node dissection is a safe, feasible and oncologicallycamparable with open gastrectomy. A large scaled prospective randomized trial should be needed to confirm the benefit of LADG.

Key Words: Advanced gastric cancer, Gastric neoplasms, Laparoscopy-assisted distal gastrectomy, Noncompliance rate

Laparoscopy-assisted distal gastrectomy (LADG), first reported by Kitano et al. in 1994, ${ }^{1}$ has been established as a standard treatment modality for early gastric cancer (EGC). However, LADG has not yet been validated in advanced stages in terms of oncological feasibility and is therefore performed in a limited number of cases of EGC with a low chance of lymph node metastasis due to the technical difficulties of systemic D2 lymphadnectomy. Previous European randomized controlled clinical trials de-
Corresponding Author: Ki Young YOON, Department of Surgery, College of Medicine, Kosin University, 262 Gamcheon-ro, Seo-gu, Busan, 602-703, Republic of Korea

TEL: +82-51-990-6462 FAX: +82-51-246-6093 E-mail: yoonkiyoung @ naver.com
Received: August 14, 2012

Revised: December 22, 2012

Accepted: January 28, 2013 
monstrated no survival benefits of D2 over D1 dissection in patients with advanced gastric cancer (AGC). Nonetheless, gastrectomy with D2 lymphadenectomy has been the standard operation for AGC in East Asian countries including Korea and Japan. LADG for AGC would be validate with technically feasible complete D2 lymph node dissection and noninferior long-term survival. Many investigators have reported the use of laparoscopic surgery in the treatment of AGC with some favorable results. ${ }^{2-4}$ There have also been many efforts to validate systemic D2 lymphadenectomy and attain a consensus among surgeons. The aim of this study was to determine the usefulness of noncompliance rate as an indicator for D2 lymph node dissection validation in laparoscopy-assisted distal gastrectomy.

\section{MATERIALS AND METHODS}

\section{Patients}

Between October and December 2010, 65 patients with gastric adenocarcinoma underwent surgery at the Department of Surgery of A University Hospital performed by a single surgeon (K. Y. Yoon). Among them, 15 patients who underwent total gastrectomy and 2 patients who underwent exploratory laparotomy were excluded from the study. We enrolled 48 consecutive gastric cancer patients who were treated by laparoscopy-assisted distal gastrectomy (LADG) or open distal gastrectomy (ODG). We performed LADG for gastric cancer below T2N1 preoperatively diagnosed by endoscopy, computed tomography, and endoscopic ultrasound. Otherwise, we did ODG for all stages of cancers. Of them, 28 patients with gastric cancer located in the middle or lower third of the stomach underwent LADG, and the remaining 20 patients underwent ODG. All patients received D2 lymph node dissection according to the Second English Edition of the Japanese Classification of Gastric Carcinoma. The Japanese Classification defines D2 lymph node dissection as clearing of the perigastric and extraperigastric lymph nodes. For tumors located in the middle third of the stomach, we resected stations $1,3,4 \mathrm{~d}, 4 \mathrm{sb}, 5,6,7,8 \mathrm{a}, 9,11 \mathrm{p}$, and 12a. For tumors located in the lower third of the stomach, we resected stations $1,3,4 \mathrm{~d}, 5,6,7,8 \mathrm{a}, 9$, $11 \mathrm{p}, 12 \mathrm{a}$, and $14 \mathrm{v}$. Informed consent was obtained from all patients. The total number of harvested lymph nodes and the number of nodes at various lymph node stations were evaluated in both groups. We also compared the noncompliance rate, defined as frequency of cases with more than one missing lymph node station according to the guidelines of "The Japanese Research Society for Gastric Cancer" (JRSGC) lymph node grouping. ${ }^{5}$ Noncompliance rate was initially used in Dutch trial for evaluating oncological quality for D2 lymph node dissection.6 We described the depth of tumor and lymph node metastasis according to the $7^{\text {th }}$ AJCC/UICC TNM staging system revised in 2010.

\section{Surgical technique}

All surgical procedures were performed by a single surgeon with experience in laparoscopy. The following standardized procedures were performed. LADG or ODG with D2 lymph node dissection was performed under general endotracheal anesthesia. LADG was performed under a pneumoperitoneum at a pressure of $12 \mathrm{mmHg}$, using five or six ports. Total omentectomy was performed in serosa-positive cases. In partial omentectomy, the greater omentum was divided proximally 5 to $6 \mathrm{~cm}$ from the gastroepiploic 
arcade toward the lower pole of the spleen using ultrasonic shears (Harmonic scalpel; Ethicon EndoSurgery, Cincinnati, OH, USA). The roots of the left gastroepiploic vessels were exposed and divided by clipping at their origin from the splenic vessels. The right gastroepiploic artery and vein were ligated at the level of the pancreas border and its root, respectively. After division of the right gastric artery, the duodenum was transected just below the pylorus using an endoscopic stapler (Endo GIA Universal 60-3.5 mm, Covidien, North Haven, Connecticut, USA).

The lymph nodes and fatty tissue along the hepatic artery (station 12a), the anterosuperior aspect of common hepatic artery (8a), the celiac axis (9), and the proximal part of splenic artery (11p) were dissected using an ultrasonic dissector. The left gastric vein was divided, and the root of the left gastric artery was exposed and divided with double clipping, thereby allowing dissection of the left gastric artery lymph nodes (7). The perigastric lymph nodes were dissected along the upper lesser curvature up to the esophagogastric junction. For this procedure, full exposure of the portal vein and common hepatic artery, ligation of the left gastric artery at its root, and exposure of the splenic artery up to the location of the root of posterior gastric artery for en-bloc resection were attempted. Billroth I gastroduodenostomy was performed via transverse minilaparotomy placed in right upper abdomen using a circular stapler (Premium Plus CEEA 28 mm, Covidien, North Haven, Connecticut, USA). For the Billroth II gastrojejunostomy, a 5-cm upper midline skin incision was made from the substernal angle, and a hand-sewn gastrojejunostomy was performed. For ODG, an upper median skin incision was made, and D2 lymph node dissection was performed in the same manner as for
LADG.

\section{Statistical analysis}

Statistical analysis was performed using the Statistical Package for Social Science (SPSS) version 17.0 for Windows (SPSS Inc., Chicago, IL, USA). Clinicopathologic variables were analyzed using the chisquare test for discrete variables and Student's t-test for continuous variables. A $P$-value $<0.05$ was considered statistically significant.

\section{RESULTS}

\section{Patient clinicopathologic characteristics (Table 1)}

There were no differences in age or sex between the two groups. Body mass index (BMI, $\mathrm{kg} / \mathrm{m}^{2}$ ) was significantly higher in the LADG group than in the ODG group $(23.7 \pm 0.49$ vs. $22.0 \pm 0.45 ; P=0.019)$. The pathologically proven depth of invasion for the LADG group included 27 cases of T1,2 (proper muscle layer invasion) and 1 case of T3 (subserosal invasion). For the ODG group, there were eight cases of T1, two cases of $\mathrm{T} 2$, five cases of $\mathrm{T} 3$, and five cases of $\mathrm{T} 4 \mathrm{a}$ $(P=0.001)$. Lymph node metastasis was found in 1 of 28 patients treated by LADG and in 8 of 20 patients treated by ODG $(P=0.015)$. Distribution of $\mathrm{T}$ and $\mathrm{N}$ stages were different in both group. Conversion from laparoscopy to laparotomy did not occur. Among the 28 patients in the LADG group, 23 (82.1\%) underwent gastroduodenostomy using a stapler, and 5 (17.9\%) underwent antecolic gastrojejunostomy using the hand sewing technique. Among the 20 patients in the ODG group, 16 (80.0\%) underwent gastroduodenostomy, and 4 (20.0\%) underwent retrocolic gastrojejunostomy. 
Table 1. Patient clinicopathologic characteristics

\begin{tabular}{|c|c|c|c|c|}
\hline \multicolumn{2}{|c|}{ Variables } & LADG $(\mathrm{n}=28)$ & ODG $(\mathrm{n}=20)$ & $P$ \\
\hline \multirow[t]{2}{*}{ Sex } & $\mathrm{M}$ & 21 & 15 & 1.000 \\
\hline & $\mathrm{F}$ & 7 & 5 & \\
\hline BMI & & $23.7 \pm 0.49$ & $22.0 \pm 0.45$ & 0.019 \\
\hline \multirow[t]{4}{*}{$\mathrm{T}$ stage } & T1 & 26 & 8 & 0.001 \\
\hline & T2 & 1 & 2 & \\
\hline & T3 & 1 & 5 & \\
\hline & $\mathrm{T} 4$ & 0 & 5 & \\
\hline \multirow[t]{4}{*}{$\mathrm{N}$ stage } & NO & 27 & 12 & 0.015 \\
\hline & N1 & 1 & 4 & \\
\hline & N2 & 0 & 2 & \\
\hline & N3 & 0 & 2 & \\
\hline \multirow[t]{2}{*}{ Anastomosis } & Billroth I & 23 & 16 & 0.856 \\
\hline & Billroth II & 5 & 4 & \\
\hline
\end{tabular}

Mean \pm SEM.

Table 2. Patient surgical outcomes

\begin{tabular}{lccc}
\hline \multicolumn{1}{c}{ Variables } & LADG $(\mathrm{n}=28)$ & ODG $(\mathrm{n}=20)$ & $P$ \\
\hline Estimated blood loss & $117.8 \pm 18.2$ & $230.0 \pm 27.2$ & 0.002 \\
Op. time (min.) & $199.6 \pm 11.4$ & $190.7 \pm 7.7$ & 0.521 \\
Retrieved LN & $35.5 \pm 2.0$ & $45.9 \pm 2.9$ & 0.006 \\
Noncompliance rate & 0.43 & 0.4 & 0.847 \\
Hospital stay (days) & 7.2 & 8.4 & 0.678 \\
First flatus (days) & 2.7 & 3.3 & 0.785 \\
Starting semi-liquid diet & 3 & 3 & 1 \\
\hline
\end{tabular}

\section{Noncompliance rate and lymph node retrieval (Table 2)}

The average number of retrieved lymph nodes was significantly greater in the ODG group $(45.9 \pm 2.9)$ than in the LADG group $(35.5 \pm 2.0)$. The noncompliance rate was $43 \%$ in the LADG group and $40 \%$ in the ODG group. There was no significant difference in the noncompliance rate between the two groups. For the ODG group, the most common station missing from lymph node retrieval at pathological examination was station 5 , followed by station $4 \mathrm{sb}$. In case of LADG group, it was station 5, followed by station $12 \mathrm{a}$.

\section{Postoperative course and short-term surgical outcomes (Table 2)}

The average estimated blood loss during surgery was significantly less in the LADG group than in the ODG group (117.8 \pm 18.2 vs. $230.0 \pm 27.2 ; P=0.002)$. No transfusions were required during or after the operations. The mean operation time was $199.6 \mathrm{~min}$ in the LADG group and $190.7 \mathrm{~min}$ in the ODG group, with no significant difference between the two groups $(P=0.521)$. The average length of hospital stay was 6.2 and 7.4 days $(P=0.678)$, and time until presence of bowel sounds and passage of flatus was 2.7 and 3.3 days post-surgery $(P=0.785)$, for the LADG group and the ODG group, respectively. The average time to toleration of a semi-liquid diet was 3 days postsurgery in both groups. $(P=1.000)$ The last three 
parameters have statistically no significant differences.

\section{DISCUSSION}

Gastrectomy with D2 lymphadenectomy has been the standard operation for AGC in East Asian countries, including Korea and Japan, despite the poor results of European randomized controlled clinical trials. ${ }^{6,7}$ The gastric cancer treatment guidelines of the Japanese Gastric Cancer Association ${ }^{8}$ recommend endoscopic mucosal resection (EMR) for patients with small mucosal cancer and no lymph node metastasis, modified gastrectomy with $\mathrm{D} 1+\alpha$ dissection for patients with differentiated submucosal cancer less than $1.5 \mathrm{~cm}$ in diameter, and $\mathrm{D} 1+\beta$ dissection for patients with submucosal cancer that does not meet these conditions. For more advanced cancer they recommended standard gastrectomy, defined as resection of more than two-thirds of the proximal, distal, or total stomach and D2 lymph node dissection according the size and location of the tumor.

There have been many efforts to expand the indications of laparoscopy-assisted distal gastrectomy to include cases of more advanced gastric cancer, although these were retrospective studies with a small number of patients and selection bias. Lee et al. ${ }^{3}$ showed that LAG for AGC has considerable benefits as a minimally invasive treatment in selected cases from their retrospective study. Hwang et al. ${ }^{4}$ reported that LADG with extended lymphadenectomy is a feasible and safe procedure for locally advanced gastric cancer. They included patients with tumors confined to the subserosal layer (T3) in terms of tumor invasion depth and with no evidence of metastases to regional lymph nodes on preoperative examination.
Their study showed several advantages in terms of shorter operation time, less estimated blood loss, shorter time to ambulation and first flatus, and duration of analgesic medication.

There have also been many efforts to validate the oncological feasibility of D2 lymph node dissection in laparoscopy. First, some retrospective studies reported that the number of retrieved lymph nodes did not differ between LADG and ODG in a single institute. ${ }^{9,10}$ Second, other investigators documented a new surrogate marker called the noncompliance rate, defined as cases with more than one missing lymph node station according to the guidelines of The Japanese Research Society for Gastric Cancer (JRSGC) lymph node grouping. Lee et al. ${ }^{11}$ demonstrated that the noncompliance rate of the LADG group was similar to that of open gastrectomy reported in a previous pilot study. Third, other researchers proposed major complication rate as an indicator to validate D2 lymph node dissection. Katai et al. ${ }^{12}$ reported favorable results of extraperigastric lymph node dissection in their multicenter phase II trial (JCOG 0703) in 2010. To demonstrate the safety and feasibility of LADG with suprapancreatic nodal dissection, they defined the primary endpoint as the proportion of patients who developed either anastomotic leakage or a pancreatic fistula They concluded that LADG performed by experienced surgeons was safe in terms of the incidence of complications

In Korea, there are two major ongoing clinical trials to extend the indication of LADG to include cases of more advanced gastric cancer. First, the COACTs study ${ }^{13}$ evaluates the feasibility of LADG with D2 dissection compared to open distal gastrectomy in advanced gastric cancer patients. Their definition of noncompliance rate is the same as that of this study. 
Second, the KLASS-02 trial ${ }^{14}$ is divided into four areas of interest: surgeon's validation, analysis of morbidity and mortality, quality of life, and evaluation of disease-free survival. These two trials have certain aspects in common, such as a criterion for participating surgeons and surgical outcomes including morbidity, mortality, and disease-free survival. As a result of ongoing clinical trials and those that will be conducted in the future, the indications for LADG might be extended to include more advanced gastric cancer in selected conditions.

The present study has some limitations. Patients were assigned to both groups according to preoperative staging in a different distribution ratio. In other words, more patients with EGC were assigned to LADG group. Because of our policy to select the procedure type, a small number of patients of advanced stage received laparoscopy. However, there were no problems when comparing noncompliance rate between the two groups because noncompliance rate is not related to lymph node metastasis. Additionally, there was a discrepancy in the number of retrieved lymph nodes between the two groups. The reason of this phenomenon is that we performed total omentectomy in case of open distal gastrectomy of advanced stage. This problem could be solved in a well-designed randomized controlled trial.

In conclusions, in terms of no difference of noncompliance rate, LADG with D2 lymph node dissection is a safe, feasible and oncologically camparable with open gastrectomy. A large scaled prospective randomized trial should be needed to confirm the benefit of LADG.

Acknowledgements: We thank Miss Jee Young Lee, our colleague and research nurse, for helping with data management and handling.

Disclosures: Dr. Yoon, Dr. Park and Dr. Seo have no conflicts of interest or financial ties to disclose.

\section{REFERENCES}

1. Kitano S, Shiraishi N, Kakisako K, Yasuda K, Inomata M, Adachi Y. Laparoscopy-assisted Billroth-I gastrectomy (LADG) for cancer: our 10 years' experience. Surg Laparosc Endosc Percutan Tech 2002;12:204-7.

2. Hur H, Jeon HM, Kim W. Laparoscopy-assisted distal gastrectomy with D2 lymphadenectomy for T2b advanced gastric cancers: three years' experience. J Surg Oncol 2008;98:515-9.

3. Lee J, Kim W. Long-term outcomes after laparoscopy-assisted gastrectomy for advanced gastric cancer: analysis of consecutive 106 experiences. J Surg Oncol 2009;100:693-8.

4. Hwang SI, Kim HO, Yoo CH, Shin JH, Son BH. Laparoscopic-assisted distal gastrectomy versus open distal gastrectomy for advanced gastric cancer. Surg Endosc 2009; 23:1252-8.

5. Japanese Gastric Cancer Association. Japanese Classification of Gastric Carcinoma - 2nd English Edition. Gastric Cancer 1998;1:10-24.

6. Hartgrink HH, van de Velde CJ, Putter H, Bonenkamp JJ, Klein Kranenbarg E, Songun I, et al. Extended lymph node dissection for gastric cancer: who may benefit? Final results of the randomized Dutch gastric cancer group trial. J Clin Oncol 2004;22:2069-77.

7. Cuschieri A, Weeden S, Fielding J, Bancewicz J, Craven J, Joypaul V, et al. Patient survival after D1 and D2 resections for gastric cancer: long-term results of the MRC randomized surgical trial. Surgical Co-operative Group. Br J Cancer 1999; 79:1522-30.

8. Nakajima T. Gastric cancer treatment guidelines in Japan. Gastric Cancer 2002;5:1-5.

9. Huang JL, Wei HB, Zheng ZH, Wei B, Chen TF, Huang Y, et al. Laparoscopy-assisted D2 radical distal gastrectomy for advanced gastric cancer. Dig Surg 2010;27:291-6.

10. Tokunaga M, Hiki N, Fukunaga T, Nohara K, Katayama H, Akashi Y, et al. Laparoscopy-assisted distal gastrectomy with D2 lymph node dissection following standardization--a preliminary study. J Gastrointest Surg 2009;13:1058-63.

11. Lee JH, Kim YW, Ryu KW, Lee JR, Kim CG, Choi IJ, et 
al. A phase-II clinical trial of laparoscopy-assisted distal gastrectomy with D2 lymph node dissection for gastric cancer patients. Ann Surg Oncol 2007;14:3148-53.

12. Katai H, Sasako M, Fukuda H, Nakamura K, Hiki N, Saka $\mathrm{M}$, et al. Safety and feasibility of laparoscopy-assisted distal gastrectomy with suprapancreatic nodal dissection for clinical stage I gastric cancer: a multicenter phase II trial (JCOG 0703). Gastric Cancer 2010;13:238-44.

13. COACT. Feasibility Study of Laparoscopy-assisted D2 Distal
Gastrectomy to Treat Advanced Gastric Cancer (COACT 1001). 2010 [updated 2010-06-16]; Available from: http://www. clinicaltrial.gov/ct2/show/NCT01088204?term=COACT\&rank $=3$.

14. KLASS. Standardization of D2 Lymphadenectomy and Surgical Quality Control: KLASS-02-QC. 2011 [updated January 25, 2011]; Available from: http://www.clinicaltrial.gov/ct2/show/ NCT01283893?term=KLASS\&rank=2. 